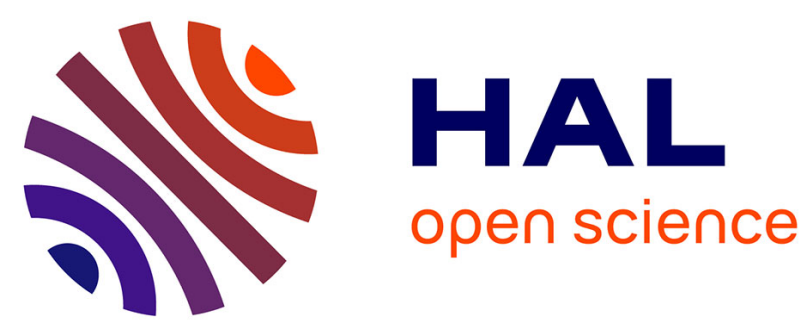

\title{
UNIAXIAL COMPRESSION OF ALUMINA : STRUCTURE, MICROSTRUCTURE AND STRAIN RATE
}

A. Cosculluela, J. Cagnoux, Francis Collombet

\section{- To cite this version:}

A. Cosculluela, J. Cagnoux, Francis Collombet. UNIAXIAL COMPRESSION OF ALUMINA: STRUCTURE, MICROSTRUCTURE AND STRAIN RATE. Journal de Physique IV Proceedings, 1991, 01 (C3), pp.C3-109-C3-116. 10.1051/.jp4:1991314 • jpa-00249943

HAL Id: jpa-00249943

https://hal.science/jpa-00249943

Submitted on 1 Jan 1991

HAL is a multi-disciplinary open access archive for the deposit and dissemination of scientific research documents, whether they are published or not. The documents may come from teaching and research institutions in France or abroad, or from public or private research centers.
L'archive ouverte pluridisciplinaire HAL, est destinée au dépôt et à la diffusion de documents scientifiques de niveau recherche, publiés ou non, émanant des établissements d'enseignement et de recherche français ou étrangers, des laboratoires publics ou privés. 


\title{
UNIAXIAL COMPRESSION OF ALUMINA : STRUCTURE, MICROSTRUCTURE AND STRAIN RATE
}

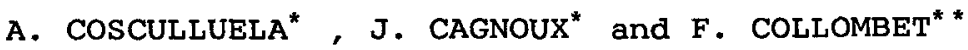 \\ *DGA/Centre d'Études de Gramat, F-46500 Gramat, France \\ * "Laboratoire de Mécanique Physique, Université de \\ Bordeaux I, URA CNRS 867, 351, Cours de la Libération, F-33405 \\ Talence, France
}

\begin{abstract}
RESUME : Deux qualités d'alumine pures à $99,7 \%$ ont été étudiées en compression uniaxiale. Pour cela trois types d'expérience ont été utilisés : la compression quasi statique, les barres d'Hopkinson, l'impact sur barreau long. Ces essais montrent que la résistance à la rupture de l'alumine croît avec la vitesse de sollicitation imposée à l'éprouvette mais décrôt lorsque la porosité et le volume de l'éprouvette d'alumine testée augmentent. Les observations M.E.B. des fragments récupérés montrent que les micro et macrofissures sont transgranulaires. Les observations M.E.T. n'ont révélé aucune activité microplastique pour chacun des trois types d'essai.
\end{abstract}

\begin{abstract}
Two kinds of $99.7 \%$ pure alumina were studied under uniaxial compression. Three types of experiments were performed : quasi static tests with a compressing machine, Hopkinson Bar tests, Impacts onto long rods. These tests show that fracture strength of alumina increases when the strain rate increases, when the porosity of the sample decreases and when the volume of the sample decreases. S.E.M. examinations of the recovered fragments show that micro and macrocracks are transgranular. T.E.M. examinations show no microplasticity in each case.
\end{abstract}

\section{1 - INTRODUCTION}

Our purpose is to study the uniaxial compressive behaviour of alumina. For this, three types of experiments were performed : quasi static tests with a compressing machine, Hopkinson Bar tests, Impacts onto long rods with a gas gun. Numerical simulations were carried out to know the stress state in the samples. Recovery-tests were performed in order to examinate post-mortem samples by optical, electronical and transmission microscopies.

This paper describes the macroscopic and microscopic results achieved with the three types of experiments. In the last section we discuss the fracture strength of alumina under uniaxial compressive stress state.

\section{2 - QUASI STATIC COMPRESSION}

\subsection{Principle}

The tests were performed with a $500 \mathrm{kN}$ compressing machine SCHENCK. Parallelism defaults of the two $18 \mathrm{~cm}$-dia. plates is $2 \mu \mathrm{m}$. We used tungsten carbide cone-shaped discs between the plates and the alumina samples. Axial and transversal strains were 
measured with CEA 13-015 VISHAY gauges. Two kinds of sample shape were used : $10 \mathrm{~mm}-$ dia. $x 20 \mathrm{~mm}$-long cylindrical samples and dumb-bell shaped specimens having over-all dimensions of $11 \mathrm{~mm} \times 4 \mathrm{~mm}$ with a gauge length of $7 \mathrm{~mm}$ and gauge diameter of $3 \mathrm{~mm}$.

\subsection{Results}

The materials tested were the two commercial aluminas AL23* and T299**. Their properties were given by the authors in another paper ${ }^{1}$. The quasi static fracture strength is $(2.8 \pm 0,2) \mathrm{GPa}$ for alumina AL23 and $(3.0 \pm 0.3) \mathrm{GPa}$ for alumina T299 in the case of cylindrical samples. For dumb-bell shaped specimens, the fracture strength is $(3.5 \pm$ $0.1) \mathrm{GPa}$ for AL23 and $(3.2 \pm 0.1) \mathrm{GPa}$ for T299. These values were achieved at $10^{-6} \mathrm{~s}^{-1}$ strain rate and are in agreement with those obtained by M. ADAMS for AL995 alumina ${ }^{2}$. The mean volume of the recovered fragments is, for each specimen, about $3 \mathrm{~mm}^{3}$ for cylinders and lower than $1 \mathrm{~mm}^{3}$ for dumb-bell shaped specimens. No microplasticity was detected by T.E.M.. S.E.M. observations showed few microcracks into these fragments. Fracture is transgranular for the two aluminas, with numerous cleavage marks in alumina AL23.

\section{3 - HOPKINSON BAR COMPRESSION}

This test stems from B. Hopkinson's work in 1914. Kolsky gave the Hopkinson Bar test its current form with its classical measurements in 1959. Today it is a well known technique for studying the yielding of metals ${ }^{3}$.

\subsection{Principle}

Many papers ${ }^{4}$ have been written about this test. We will not describe it but only note that classical measurements require the verification of many conditions, among others :

a. the behaviour of the two bars must remain elastic,

b. the stress field must be uniaxial, uniform, equilibrated in the specimen.

We also have to note that the measurements give a one-dimensional mean stress and strain value.

We know that the higher the specimen strain is, the more correct the analysis will be. This condition is ideal when the tested material is very ductile with a low elastic limit. But how can we use this test for studying a material with high mechanical properties such as alumina?

Our experimental device ${ }^{5}$ (Figure 1) is made of two $20 \mathrm{~mm}$-dia. $\times 1 \mathrm{~m}$-long $18 \mathrm{H} \mathrm{MARVAL}$ steel bars and a $180 \mathrm{~mm}$ long striker. This striker is propelled by a compressed-air gun and impacts the incident bar with a velocity of about $16 \mathrm{m.s}^{-1}$. The wave generated in the bar is called, in its steady form, a "bar wave" and its velocity is equal to $C_{B}=\sqrt{E} / p$, where $E$ and $\rho$ are respectively the Young's modulus and the mass density of the bar. Two strain gauges $A$ and $B$ provide the incident wave and reflected wave profiles. The strain gauge $C$ of the transmission bar supplies the axial stress in the sample.

The fracture strain of the sample is so low that it cannot be calculated by classical Kolsky-Hopkinson measurements. So two strain gauges were bonded over each sample to obtain axial and transversal strains. To avoid shallow indentation of the alumina in the steel, we put two $20 \mathrm{~mm}$-dia. $\times 2 \mathrm{~mm}$-long tungsten alloy discs between the sample and the bars.

* DEGUSSA FRANCE - 37, Avenue Marceau 92402 COURBEVOIE CEDEX

** C.I.C.E. - 63, Rue Baumarchais - BP N 6993104 MONTREUIL CEDEX 


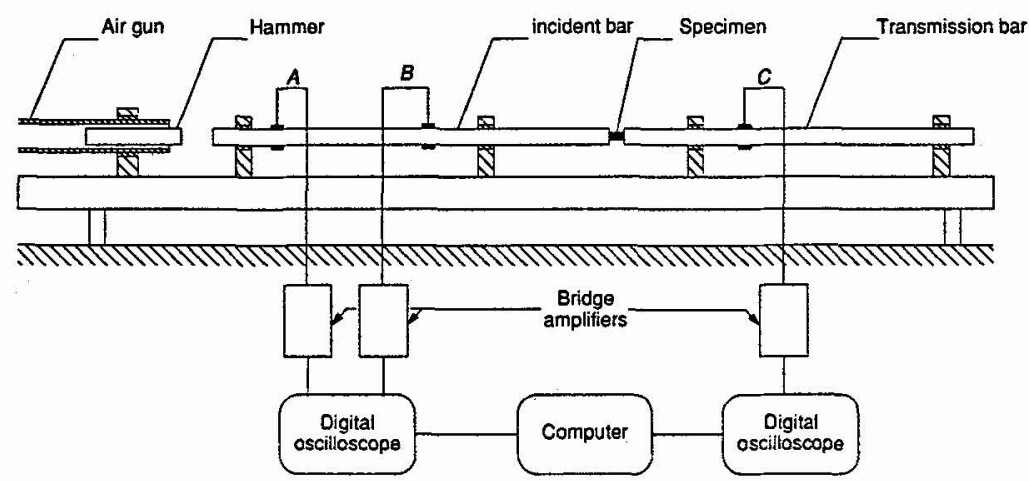

FIG. 1 : Experimental set-up

\subsection{Numerical simulations}

The aim of these simulations was to define an optimal sample shape to obtain a uniform uniaxial stress field and to reach the fracture stress. The simulations were performed with the industrial finite element code ABAQUS. Figure 2 shows the state of the axial stress field for two alumina sample shapes used by others authors ${ }^{,}$, .

Two comments must be made here :

a. the section of the cylinder is too large to reach the supposed fracture stress of alurina using our test apparatus, and the stress field is not uniform,

b. the dumb-bell shape gives a central zone where the stressfield is uniaxial, uniform and maximum.

Furthermore, the numerical simulation shows that the strain of the transmission bar cannot be related to the stress measured in the sample using classical KolskyHopkinson analysis.
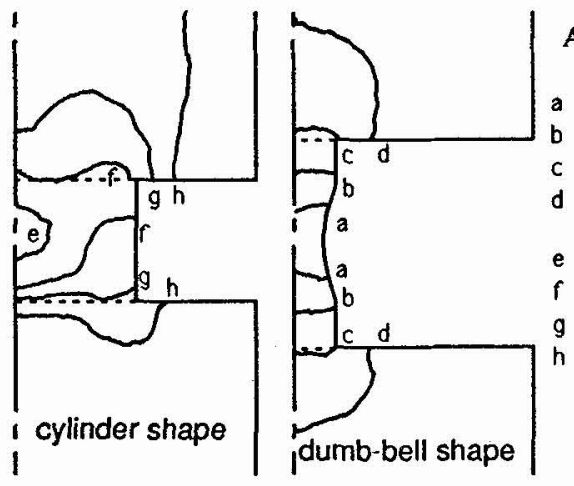

$$
\begin{aligned}
& \text { Axial stress } \\
& \text { (GPa) } \\
& -4.00 \\
& -3.20 \\
& -2.40 \\
& -1.60 \\
& -0.20 \\
& -0.12 \\
& -0.14 \\
& -0.06
\end{aligned}
$$



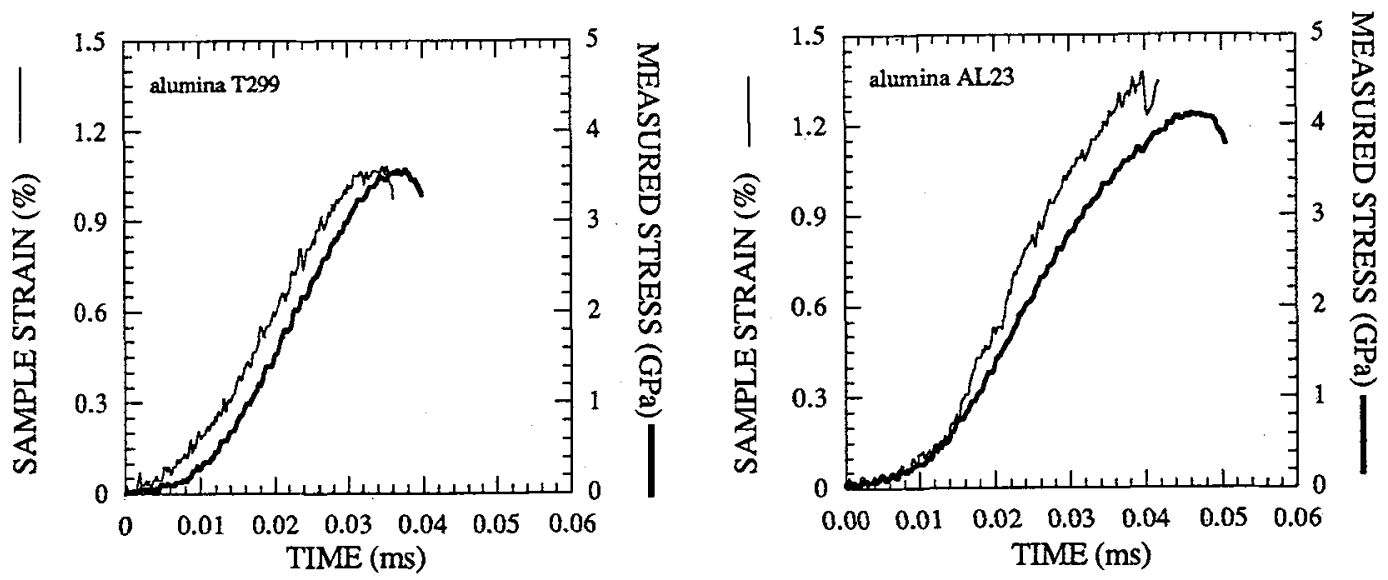

FIG. 3 : Experimental results achieved for the two aluminas with Hopkinson bar tests

\subsection{Experimental results}

The tests were performed on two series of dumb-bell shaped samples made of two different kinds of alumina (AL23 and T299). A quasi static compression test was made for each gauged sample five times below its fracture stress in order to calibrate the gauges. Then Hopkinson Bar tests were performed with an incident pulse magnitude of $0.3 \mathrm{GPa}$ and a pulse duration of $75 \mu \mathrm{sec}$. Figure 3 shows typical results achieved with the two aluminas. The reproductibility of the tests is about $3 \%$. The stress measured from the transmitted wave $\sigma_{t}=E_{b} \epsilon_{t} A_{b} / A_{s}$ (where $\epsilon_{t}$ is the strain of the transmission bar, $A_{b}$ and $A_{s}$ are bar and sample sections, $E_{b}$ is Young's modulus of the bars) is undervalued if we compare it to the true stress $\sigma=E_{c} \epsilon_{s}$, (where $E_{c}$ is the Young's modulus given by quasi static calibration tests and $\epsilon_{\mathrm{S}}$ the strain measured over the sample). The undervaluation of the stress is due to the excessive difference between the bars section and the sample section. Ratios $\sigma / \epsilon$ and $\epsilon_{\text {trans }} / \epsilon_{\text {axi }}$ remain constant during the tests.

Figure 4 shows a T299 recovered sample. Note that the previously colour-marked central zone is finely fragmented compared to the extremities. In these fragments, S.E.M. observations showed numerous microcracks compared to the case of quasi static compression. However few cleavage marks are observed. Fracture is transgranular for the two aluminas.

\section{IMPACT ONTO TWO LONG RODS}

\subsection{Principle}

This test is based upon the propagation of a steady stress wave in a finite medium. This test was performed using ductile metals ${ }^{8}$ in 1968 and more recently using ceramics 9,10 . The tests are always performed onto one long rod. In our case, with a view to using Lagrangian analysis, impacts onto two long rods were performed (Figure 5). Particular care was taken for each test in order to ensure simultaneous impact onto the rods. A V.I.S.A.R. through a PMMA window, provided the particle velocity-time profiles in the rods.

\subsection{Numerical simulations}

These numerical tests were performed in order to : 


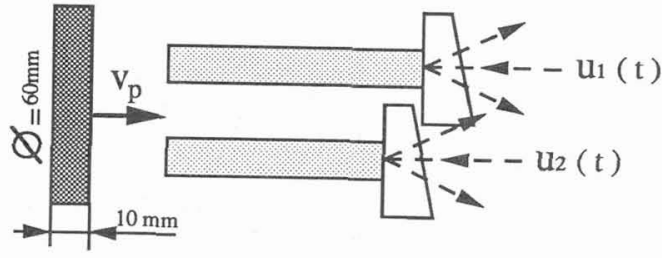

FIG. 5 : Simultaneous-Impact onto long rods device

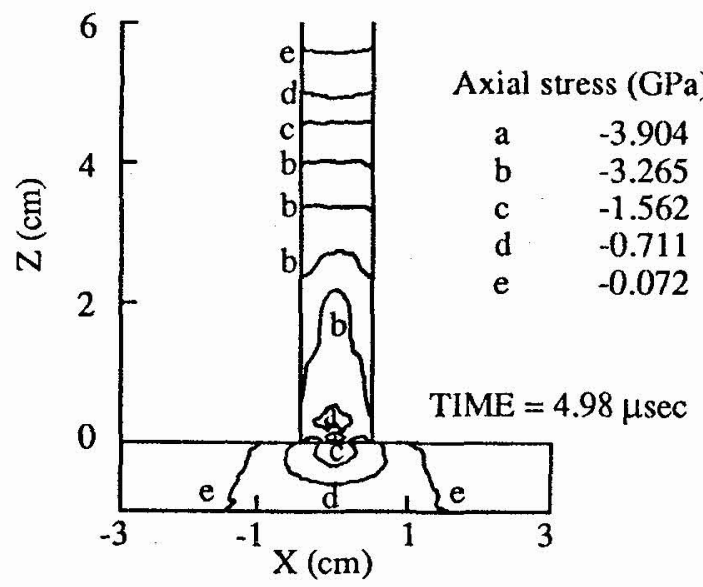

FIG, 6 : Uniaxial stress field in the rod

a. analyse the stress state in the rod,

b. adapt plate-impact VISAR measurement techniques to impact onto long rod experiments.

Two codes were used : ABAQUS and the elastic-plastic impact lagrangian code EPIC 3 . Figure 6 shows the results of the simulations carried out with the code EPIC 3 . Note that the stress state becomes uniaxial after a distance from the impact surface equal to two times the rod diameter. In order to obtain particle velocity, we corrected, as shown by numerical simulations, the interface (PMMA-alumina) velocity histories using $\mathrm{C}_{\mathrm{B}}$ and not $\mathrm{C}_{\mathrm{L}}$ as done in the case of plate impact.

\subsection{Simultaneous-Impact test results}

Tests were performed with $1 \mathrm{~cm}$-dia. $\times 8 \mathrm{~cm}, \times 10 \mathrm{~cm}, \mathrm{x} 12 \mathrm{~cm}$ long rods made of the two aluminas. Impact velocities $V_{p}$ of the flyer onto the rods were $80,200,400$ and $700 \mathrm{~ms}^{-1}$. The measured velocity level was the same for $400 \mathrm{~ms}^{-1}$ and $700 \mathrm{~ms}^{-1}$ tests.

Figure 7 shows typical material velocity-time profiles for each alumina. Note the presence of a shock precursor at the begining of the record. This is the rest of the longitudinal wave $\mathrm{C}_{\mathrm{L}}$ generated at the moment of impact. The level of this precursor depends on the impact velocity and on the point of measurement. Figure 8 shows a polished recovered fragment. Successive observations of parallel, closed, polished surfaces showed that numerous microcracks were nucleated inside the sample and did not originate from surface faults. These microcracks are transgranular (Figure 9). In the case of alumina T299 some microcracks are intergranular near the finest grains. No microplasticity marks could be observed by T.E.M.

\section{5 - DISCUSSION}

\subsection{Cylindrical samples}

\subsubsection{Quasi static tests}

The mean volume of the recovered fragments is about $3 \mathrm{~mm}^{3}$. Few microcracks could be detected by S.E.M. observations. Fracture is due to surface defaults, sintering defaults and pores. 

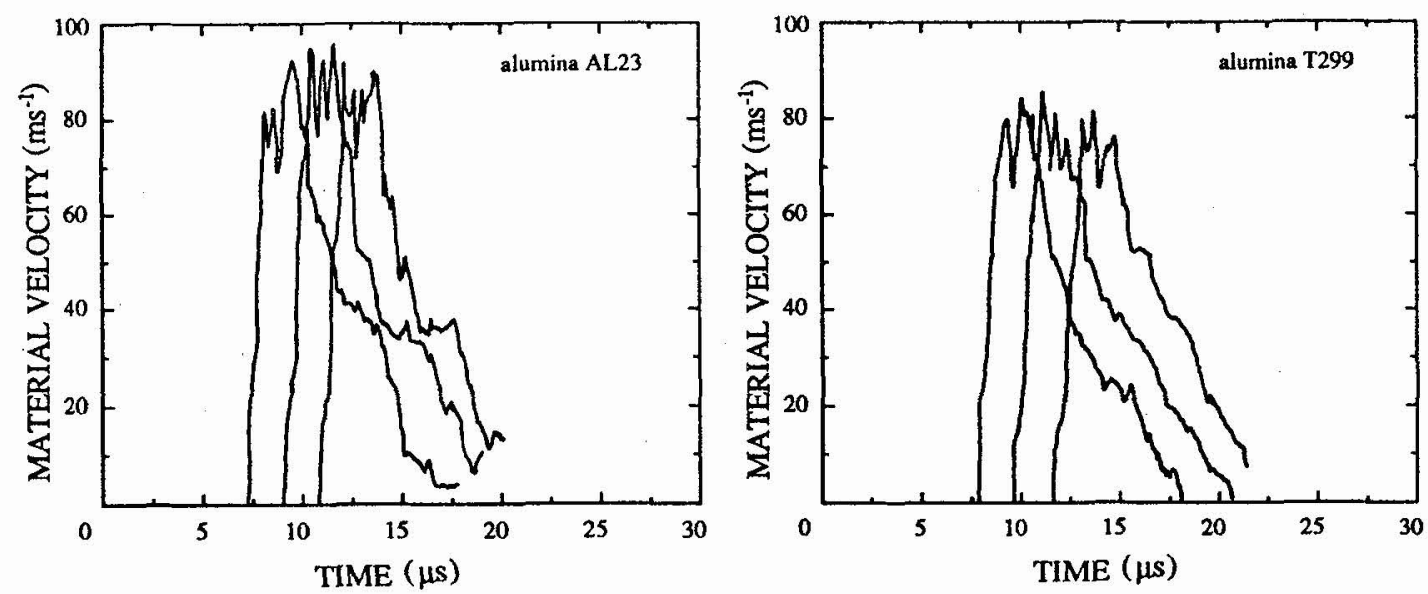

FIG. 7 : Material velocity-time profiles obtained for the two aluminas with impacts onto $8 \mathrm{~cm}, 10 \mathrm{~cm}, 12 \mathrm{~cm}$ long rods.

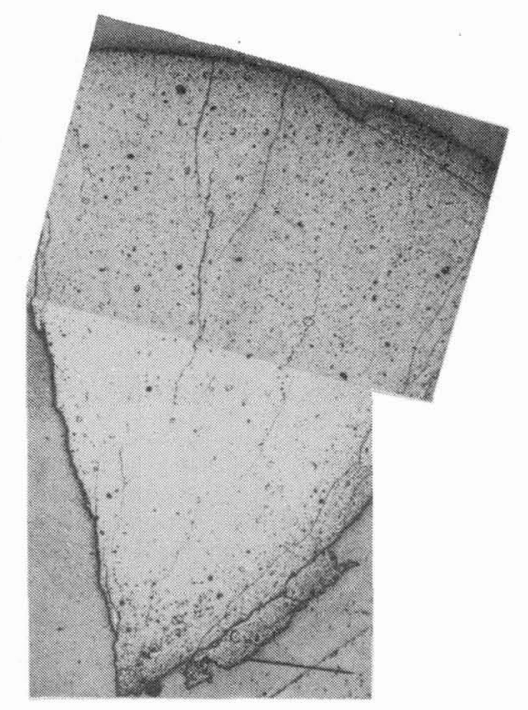

Fig. 8 : Polished recovered fragment of alumina T299

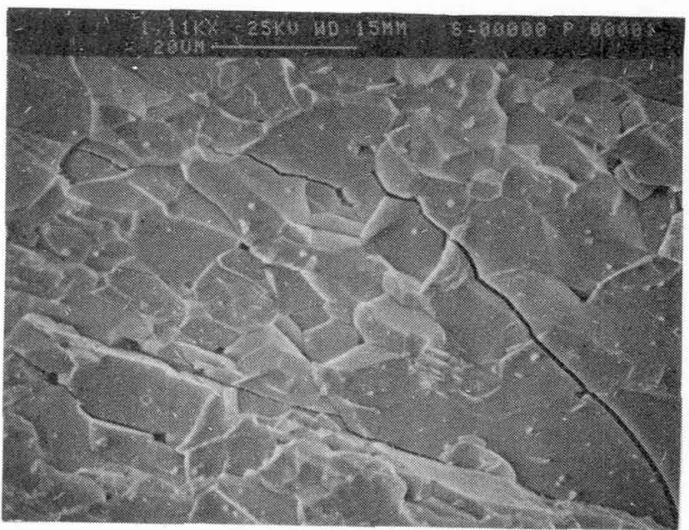

FIG. 9 : Transgranular fracture in alumina AL23

\subsubsection{Dymanic tests (impact onto long rod)}

The geometry of the recovered fragments is shown on the figure 8 . The length of the fragments is $3-10 \mathrm{~mm}$. Numerous in-material microcracks were detected. We showed that these microcracks were nucleated inside the sample and essentially originated from pores.

\subsubsection{Influence of the strain rate}

Although the mechanism of fracture is different between quasi static and dynamic tests, no significant strain rate effect exists for alumina T299. For alumina AL23 the fracture stress increases with strain rate. 


\subsection{Dumb-bell shaped samples}

\subsubsection{Quasi static tests}

The mean volume of the recovered fragments is about $1 \mathrm{~mm}^{3}$. Few microcracks were detected. Fracture originates from surface defaults, sintering defaults and pores.

\subsubsection{Dynamic tests (Hopkinson Bar)}

The recovered fragments have no particularly form, their mean size is about $0.1 \mathrm{~mm}^{3}$. Microcracks are numerous compared to the case of quasi static compression. We could not show if the fracture is due to in-material defaults or surface defaults.

\subsubsection{Influence of the strain rate}

For the dumb-bell shaped sample and for the two aluminas, the fracture stress increases highly with strain rate.

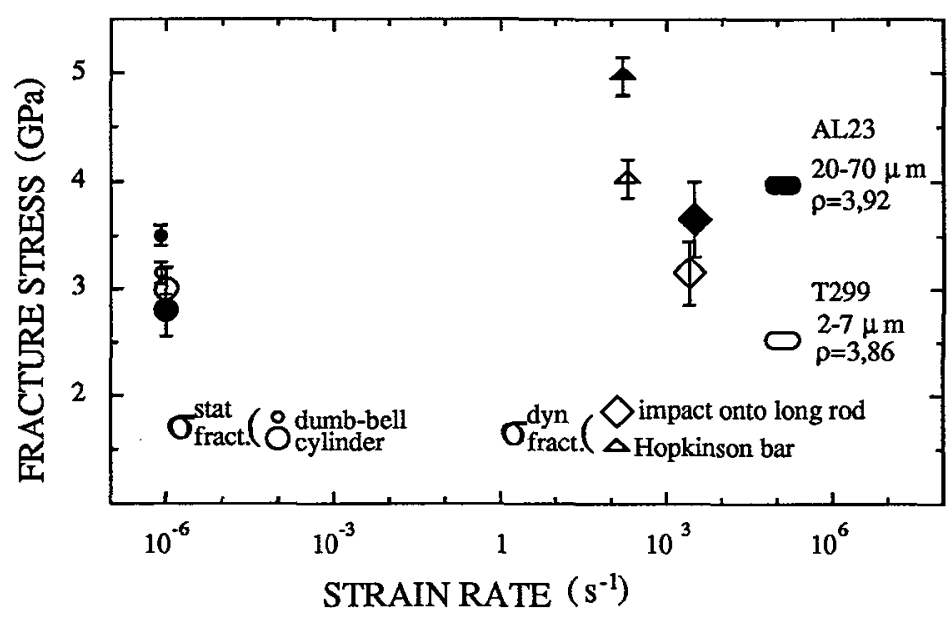

FIG. 10 : Fracture strengths of alumina

\section{6 - CONCLUSION}

For all the tests, the fracture stress of the dumb-bell shaped samples is higher than the fracture stress of cylindrical samples. The scale-effect plays an important role for this type of material.

Figure 10 shows that alumina fracture stress $\sigma_{f}$ increases with the strain rate, and with the density. If we assign a fracture stress of T299 to the density of AL23 via the relation $\sigma_{f}=\sigma_{o} e^{-b P}$, where $\sigma_{o}$ and $b$ are alumina constants and $\mathrm{P}$ the porosity, we can conclude that there is no major effect of grain size on macroscopic behaviour of alumina, except the case of T299 cylindrical samples.

In conclusion, it is difficult to reach an intrinsic uniaxial dynamic compressive fracture stress of alumina. The three types of experiments provided a fracture stress of a given sample made of a well known material submitted to a well defined stress and strain state. 


\section{ACKNOWLEDGEMENTS}

The authors wish to thank S. CHAMBAUDIE and C. BODIN for undertaking impact onto long rod tests and E. BUZAUD for performing the numerical simulations with the code EPIC3.

\section{REFERENCES}

1 - A. COSCUlluela, J. CAGNOUX, F. COLLOMBET "Two types of experiments for studying dynamic compression of alumina". To be published in the proceeding of 1991 conf. on shock compression of condensed matter 16-20 June 1991. Williamsbury, U.S.A. (Elsevier science Published, B.V., Amsterdam, 1991).

2 - M. ADAMS, G. SINES "Determination of biaxial compressive strength of sintered alumina ceramic". J.A.C.S $\underline{59}$ (1976) 300-304.

3 - A. LICHTENBERGER, G. GAZEAUD, E. LACH, "Essais de compression sur barres d'Hopkinson : simulation numérique et étude expérimentale". Proceedings of 1988 DYMAT Conference, pp 589-594, (1988).

4 - P.S. FOLLANSBEE, "The Hopkinson Bar" in Metals Handbook, Vol 8, 1985,pp 198-203.

5 - C. BACON, "Rupture dynamique des matériaux fragiles à haute température". Ph. D. Thesis. University of Bordeaux I, (1992). To be published.

6 - W.R. BLUMENTHAL, G.T. GRAY III, "Structure- property characterization of shockloaded $\mathrm{B}_{4} \mathrm{C}-\mathrm{Al}$ ". Proceedings of the Fourth. International Conference on the Mechanical Properties of Materials at High Rates of Strain, Oxford 19-22 March 1989.

7 - J. LANKFORD, J. Mat. Sci. 12 (1977) 791.

8 - O.W. DILLON Jr., "Plastic deformation waves and heat generated near the yield point of annealed aluminium". In Mechanical behavior of materials under dynamic loads. Ed by U.S. LINDHOLM (1968).

9 - N.S. BRAR, S.J. BLESS, Z. ROSENBERG, "Brittle failure of ceramic rods under dynamic compression". Proceedings of 1988 DYMAT Conference, pp. 607-612, (1988).

10 - L.R. DEOBALD, M. TAYA, A.S. KOBAYASHI, H.S. YOON, "Spall resistance of alumina". Technical report. N. UWA/DME/TR89/1. Office of the chief of Naval Research (1989). 